Title: Entrepreneurship in nature-based tourism under a changing climate

Author:

Kaarina Tervo-Kankare

Geography Research Unit, University of Oulu, Finland

P.O Box 3000, 90014 University of Oulu, Finland

kaarina.tervo-kankare@oulu.fi

+358503507159

Acknowledgements

This paper is based on research funded by the Academy of Finland under the FiDiPro programme 'Human-Environment Relations in the North: resource development, climate change and resilience', and under the CLICHE-project (Impacts of Climate Change on Arctic Environment, Ecosystem Services and Society). I would like to thank the anonymous reviewers and the editors for their comments and help in polishing and revising this article. 


\title{
Title: Entrepreneurship in nature-based tourism under a changing climate
}

\begin{abstract}
This paper presents the findings of an exploratory study examining the values and attitudes of nature-based tourism entrepreneurs in relation to adaptation to climate change. The aim is to focus on tourism stakeholders' values and ideas about tourism entrepreneurship, which may bring interesting new insights to the tourism and climate change research and support the industry in adaptation and mitigation processes. The data utilised in this paper consists of nineteen thematic interviews conducted with nature-based tourism entrepreneurs in Finland between 2009 and 2013. Analysis of the data reveal issues concerning views on entrepreneurship in general, on the independence and individuality of the enterprises, on the roles and responsibilities of different stakeholders in the processes of adaptation and on the attitudes towards innovations and actions in the changing climate. These issues, together with the rate and scale of the change, seem to affect decision-making by the enterprises, but their importance as predictors of action and behavioural intentions needs to be studied more thoroughly. Additionally, more information is required regarding the role of the surrounding social environment as a co-creator of these kinds of values. However, the study supports previous studies on entrepreneurship and its influence on survival and resilience.
\end{abstract}

Keywords: nature-based tourism, entrepreneurship, adaptation, climate change, global environmental change, resilience 


\section{Introduction}

Climate change represents an issue of significant concern for nature-based tourism and calls for adaptive capacity in the tourism sector. While the sector consists of several stakeholders being affected by the changing climate, the role of the operators in tourism, i.e. the tourism businesses, is emphasised in relation to the concepts of adaptation and mitigation. The other actors, such as travel agents, tourists, tourism developers, host communities and decision-makers at different levels (from local to international) have different, although equally important roles in adjusting the industry as it transitions into the era of climate change.

The businesses' responses to challenges brought by the changing climate have been addressed in several studies (see e.g. Kajan \& Saarinen, 2013). According to a majority of these studies on nature-based tourism entrepreneurs, the level of action in the sector has remained low, despite the growing awareness and understanding of the causes and consequences of the phenomenon. Several studies on climate change risk perceptions in general (e.g. Leiserowitz, 2006) and on climate change awareness among tourism stakeholders (e.g. Becken, 2005; Hall, 2006; Saarinen \& Tervo, 2006; Hambira, Saarinen, Manwa \& Atlhopheng, 2013; Hübner, 2014) have concluded that knowledge and awareness about climate change does not necessarily lead to action. Awareness of climate change and its potential risks may be at a high level, but the stakeholders show no signs of proactive action (adaptation or mitigation). Therefore, it seems that awareness alone does not lead to action, but other issues have an equally important, or even more important role in decisionmaking.

One reason for the inactivity of stakeholders may relate to entrepreneurship, or the values associated with it. Even though tourism entrepreneurship has not been extensively studied 
(Ateljevic \& Li, 2009; Solvoll, Alsos \& Bulanova, 2015), many studies indicate that especially nature-based tourism entrepreneurs have certain characteristics and values that may affect (rational) decision-making processes (Ateljevic \& Doorne, 2000; Bredvold \& Skålen, 2016; Iversen \& Jacobsen, 2016; Lundberg \& Fredman, 2012; Reijonen \& Komppula, 2007). In addition, values are considered to hold an important role as psychological stimuli for the development of risk perceptions and behavioural intentions (Leiserowitz, 2006). Therefore, an approach that focuses on the tourism stakeholders' and their social environments' values may bring interesting new insights into tourism and climate change research. Moreover, these insights may bring needed support for the industry in adaptation and mitigation processes.

The aim of this article is to examine the entrepreneurs' considerations about their survival in the changing climate, and, more importantly, to reveal their attitudes towards the requisites of this survival. Rather than examining the specific methods of adaptation, as has been done in several previous studies, this article focusses on analysing the potential forces leading to these kinds of adaptation strategies. Thus, the attitudes and valuation of entrepreneurship, nature and environment and collaboration in tourism, as well as the considerations about the state and other agencies as creators or enablers of environments that support adaptation are examined in this paper.

Moreover, this paper aims to bring new insights to the study of environmental engagement in tourism research. As Sampaio, Thomas and Font (2012) state in their paper on small business management and environmental engagement, the research of the factors that influence tourism enterprises' engagement (and actions) in environmental issues has remained on a low level, despite the growing interest towards sustainability in tourism research. Therefore, the abovementioned forces that lead to action in adaptation are assessed also from this point of view. If entrepreneurs can act as change agents in social and economic systems (see Vesala \& Niska, 2013), is it possible 
that they can also act that way in terms of environmental issues, and what are the factors that potentially hinder or enhance engagement and consideration of environmental issues?

\section{Tourism enterprises, entrepreneurship and adaptation}

Lifestyle factors are considered to be highly important in tourism enterprises, from the starting of a business to decision-making and perceptions concerning, e.g., success and development (Ateljevic \& Doorne, 2000; Bredvold \& Skålen, 2016; Iversen \& Jacobsen, 2016; Lundberg \& Fredman, 2012; Reijonen \& Komppula, 2007; Solvoll, et al., 2015). Reijonen and Komppula (2007), for example, in their study on the perceptions of success in small rural craft and tourism businesses, outline that entrepreneurs' characteristics, motives, goals and attitudes impact their understandings of success. They conclude that success is primarily measured according to customer satisfaction and respect, but that also job satisfaction plays an important role. In addition, making a profit is not considered important in comparison to 'making a living', spending time with family, freedom and independence.

Businesses and their perceptions, preferences and decision-making are increasingly important perspectives also in research that addresses global environmental change (GEC) and global climate change (GCC). Adaptation and mitigation are needed in order to sustain tourism in the changing environment, but research has not been able to pinpoint the specific factors affecting decisionmaking that relates to either of these aspects. Awareness studies (e.g. Hall, 2006; Saarinen \& Tervo, 2006; see also Dodds \& Graci, 2009; Saarinen \& Tervo, 2010) have been able to create some linkages between GEC or GCC action among tourism businesses, while costs were presented to have an equally important role in the decision-making of entrepreneurs studied by Kaján, TervoKankare and Saarinen (2014; see also Tervo-Kankare, Kaján \& Saarinen, 2017). In addition, the 
need for collaboration has been emphasised in several research reports and articles (Browne \& Hunt, 2007; Becken, 2008; Pollock, 2008), but again, research evidence concerning collaboration in terms of climate change adaptation is rather limited (see Scott, Gössling \& Hall, 2010; TervoKankare, 2011).

Further, Brouder and Lundmark (2011), who studied intraregional differences among tourism operators, found that attitudes towards climate change depended on the type of the business: venuebased enterprises saw climate change as a more threatening phenomenon than activity-based enterprises. Similarly, Tervo (2008) found differences in tourism operators' attitudes and reactions to climate change in regard to type of activities provided. However, in both studies the explanatory factors creating these differences were searched for from within the operational environment rather than from aspects relating to entrepreneurship.

Adaptation has a close interrelationship with the concept of resilience, which in this article is understood in its socio-ecological context as 'the capacity of a system to absorb disturbance and reorganize while undergoing change so as to still retain essentially the same function, structure, identity, and feedbacks' (Walker, Holling, Carpenter \& Kinzig, 2004: no page; see also Burnard \& Bhamra, 2011). Resilience studies have also dealt with entrepreneurship, and some of them suggest that entrepreneurial characteristics can be essential for the development of resilience. McNaughton and Gray (2017: 3), for example, examined entrepreneurship and resilience, and emphasise that these two concepts have shared attributes, namely flexibility, adaptiveness, proactivity and innovativeness. Bakas (2017) has confirmed that entrepreneurship may increase community resilience in the context of an economic crisis. In addition, Steiner and Atterton (2015) state that rural business owners have certain characteristics (mainly motivation and resources) that help them turn challenges into entrepreneurial opportunities; thus, their influence on (community level) 
resilience is positive. Even though these studies cannot (and should not!) be directly applied to this context, the concept of resilience and resilience approaches are considered useful for studies focusing on the future of tourism in changing climate (Becken, 2013; Hall, Prayag \& Amore, 2017). Thus, this study, with its focus on nature-based tourism - a socio-economic system relying strongly on natural environments - also touches upon this concept.

Entrepreneurship with its 'hidden' characteristics and factors, may affect all kinds of decisionmaking in tourism, especially in regions where nature-based tourism forms the core of tourism activities. Besides consisting largely of small- and medium-sized enterprises (SMEs) (or even small and micro enterprises!), the nature-based tourism sector has also been characterised by lifestyle entrepreneurs, to whom the making of a profit may be irrelevant in comparison to other reasons for setting up businesses (Shaw \& Williams, 2004; Lundberg \& Fredman, 2012: 650; Reijonen \& Komppula, 2007; Sampaio et al., 2012). These more relevant reasons include 'being their own bosses', maintaining certain lifestyles, and being consistent with socio-political ideologies (Shaw \& Williams, 2004). It is possible that these attributes act as factors in climate change -related decisionmaking as well, thus contributing to adaptation and resilience. Therefore, in this article, these other attributes linked with being an entrepreneur in nature-based tourism are studied. The term 'entrepreneurship' does not only refer to operations with a commercial standpoint where risk-taking and profit-growth hold a central role, but also to attributes that are connected to the term in different approaches: agency, innovations, and independency (Vesala \& Niska, 2013). However, both the terms 'entrepreneurship' and 'entrepreneur' in this article follow the traditional ideas of entrepreneurial activity (Schumpeter, 1934; Vesala \& Niska, 2013), as the choice of informants has been realised on the basis of this definition. The wider understandings of entrepreneurship, as discussed, for example, by Jones and Spicer (2009) or Hjorth (2003) could also be applied in this context. 


\section{Research methods and data}

In Finland, microenterprises (less than 10 employees, turnover equalling less than 2 million euros) dominate the tourism sector (Vesterinen, 2017). The same applies to nature-based tourism, even though the statistics concerning this sector are not well established (Petäjistö \& Shelby, 2012). The dependence of tourism operations on natural resources is evident, even though the resources used in tourism differ. However, their vulnerability to changes caused by climatic changes is very similar: warming and weather variability reduce the attractiveness of the destinations and endanger/hinder the production of tourism activities.

The data utilised in this study consists of thematic interviews that were realised in Northern Europe, in Finland (Lapland and Central/Lake Finland) between 2009 and 2013. The main aims of these interviews were to reflect nature-based tourism entrepreneurs' attitudes to climate change and climate change adaptation, to study their responses and reactions to climate change and climate variability, and to assess the needs for cooperation and support in these businesses. In addition, the 2013 interviews also examined the costs and benefits of climate change -related environmental phenomena.

The entrepreneurs in the 2009 study were selected utilising the so-called snowball method, where the representatives of the destinations' focal enterprises and tourism developers were asked to suggest tourism entrepreneurs whose participation in the destination's development they considered significant. These entrepreneurs were also given the possibility to make further recommendations about the respondents. Altogether nine entrepreneurs agreed to participate in the study in two Finnish tourism destinations located in Lapland (Levi, 7) and in Central Finland (Himos, 5). In 
addition, 10 tourism enterprises in Saariselkä village in Northern Lapland were interviewed during another research project in 2013-2014, and these interviews were included in this study. In Saariselkä, all tourism enterprises registered in Saariselkä were contacted, but not all were willing to participate in the study, and some preferred to give their answers via email, or via a web-survey. These responses were not included in this study, as the depth of data collected this way did not support the use of qualitative content analysis. In addition, as three of the interviewees in Levi and Himos were not entrepreneurs themselves, but were company representatives, their answers were omitted from this study. Thus, the final number of entrepreneurs participating in this study was 19 (5 from Levi, 4 from Himos and 10 from Saariselkä). In all these destinations, winter is the dominating season.

Table 1 about here.

All interviews were taped and transcribed for the analysis. Data were analysed using qualitative content analysis with the main aim of spotting issues addressing reasoning for environmental action, especially adaptation and the importance of the surrounding (social) environment for the development and enforcement of these actions. In addition, the data were searched for comments/opinions that related to the above-discussed lifestyle factors linked with entrepreneurship. The data were analysed with the help of software, which made it easier to reveal connections between the different themes and the interviewees.

\section{Results}

Entrepreneurship - Doing your 'own stuff' 
In most companies participating in the study, the owners' personal interests had an important role in the starting of the business. Previous hobbies (such as hiking, skiing, canoeing, dog sledding, etc.) often formed the basis of the enterprise's operations, rather than previous occupation. However, this mostly applied to programme service and skiing entrepreneurs. In some family-enterprises the current entrepreneurs stated they had grown up in the business.

'So in (19)97 I set up a company. And I thought that I will continue to take women to the fell as I had done for more than a decade already, but so that I can also receive real cash, not just linen towels, when I take people out (to the fells) for a week, so that my knowhow was going pretty cheap. So that I thought that I could maybe gain a few coins more from that.' (microentrepreneur, Lapland, previous occupation in public sector as a social worker)

'No, I don't have [a degree in tourism], in my previous life I was making paper at United Paper Mills and my vocational education is for the paper industry. So, this entrepreneur thing is selflearned and in a sense started from my background in dog sled races. So, I have made my hobby into my profession.' (microentrepreneur, Lapland)

'Well, to be honest, I have scurried here since I was a kid, but as an entrepreneur I started that year.' (small entrepreneur, Central Finland)

Moreover, rather than having an applicable education (e.g. degree in tourism) most entrepreneurs stated they had learned by doing. Also, many entrepreneurs mentioned that they had participated in local/regional employment offices', or colleges'/training centres' short courses aimed at tourism entrepreneurs. This applied also to bigger enterprises, but not always. Interestingly, their workers often had more applicable degrees. Learning by doing also meant that the entrepreneurs considered themselves to be experts in their own businesses and operations only, and were hesitant to present strong ideas about climate change; they rather left the speculations to researchers. 
Family members were often mentioned as co-workers or part-time helpers during the high season in all kinds of enterprises, and also the ex-owners (e.g. parents) still sometimes participated in the operations. In general, family was in some form mentioned in all but the two one-person enterprises. Therefore, family, family ownership and family traditions played an important role in the enterprises.

'And then it is probably so that in that way her [owner's wife] also, this place, is also her life work... so that she came from [that city] to study at Jyväskylä University but then this learning at the “company's university” has swept her up and pulled her along.' (entrepreneur, Central Finland)

'This place [organic farming, accommodation, restaurant and wine production] is my father's home farm...I am in a sense a returnee, as I was born in Helsinki and grew up in Western Finland and did not move here until year (19)90, but spent all my childhood summers here so I consider myself local.' (microentrepreneur, Central Finland)

'But then our own people, my brother and the sister who live here or nearby, they also help if we have big things.' (microentrepreneur, Lapland)

The interviewees were proud of their companies, of the things they had achieved and things they were doing. They wanted to offer their customers high quality activities/services. In addition, they enjoyed their work and some stated that profit-making was less important than work satisfaction. However, in the bigger companies, success was often connected to growth and compared to competing destinations' growth.

'I honestly think that I myself want to unwind in nature and I want my customers to reach the same. ... Many reasons...I want to give them experiences that help them go on and manage their lives, their daily lives...' (microentrepreneur, Lapland) 
'... when the customer is satisfied, sometimes when it is great weather... with the dog sled you are doing something... nature experiences... and you see that customers are [happy], and from kids you can tell it...so it makes you think that this is so fun that I need not receive any money from this' (small entrepreneur, Central Finland)

'But steady, we are, so that our growth curve, the volume of growth and all has been steady and the growth of turnover, all steady. For twenty-five years we've been growing steadily... and today we are the fifth biggest company in terms of turnover [among the same category of enterprises in Finland].' (entrepreneur, Central Finland)

The entrepreneurs thought that supporting funding from the government or other agencies may be problematic. Entrepreneurship means that you work hard and earn your living; one should not lean on financial support from outside. In addition, funding agencies should be careful not to skew the competition situation or unbalance operational conditions in some other way.

'Well of course this has, occasionally makes one think about how unequal the entrepreneurs are, are in Finland...there is no financial support for us, none at all so that we are completely on our own...well, then there is this one, one enterprise with a hundred dogs in Rovaniemi went bankrupt...so in that case the sponsor TE-centre, Finvera as well, has also acted really stupid so that when there was this great British boom, the impression was that enterprises from this field (dog safaris) are needed so much which was total bullshit...if we have a 3-week period when there is a need for more capacity ... So this kind of phenomenon took place and start-up money (enterprise allowance) was given...so new competitor entrepreneurs were funded, and for those [old] entrepreneurs who were just and just starting to stand on their own feet [it was fatal]. So in that way [the funders] kind of destroyed the old ones, and new entrepreneurs were funded who did not understand entrepreneurship more than a pig understands wind mills.' (microentrepreneur, Lapland) 
All interviewees were developing their services somehow. However, making more profit was not always the main aim of the development. Instead, improving quality and meeting new demands were considered the main motivators for development. The microentrepreneurs did not use typical business terms, such as amortisation times, when talking about their future development. In comparison, the representatives of the bigger enterprises more often presented their future development in relation to money, energy-efficiency, savings, material choices, etc. They also understood the differences between them and the microenterprises in regards to future development and timespans in planning.

'...it does not, if you buy twenty snow mobiles and set up your enterprise, then after five years they [snowmobiles] are ragged anyway and if this climate change has changed then you do not buy new ones. You think with a short time span. But then these [our kind of] bigger projects and this kind of business expansion, like we have now, that we really are [going to be] here for the next ten-twentyfifty years then you really have to think more carefully.' (entrepreneur, Central Finland)

\section{Values towards nature and environment}

Respect for the environment was strong among all enterprises: in the end, the natural environment is the main source of income. Maintaining and nurturing high environmental quality was mentioned on many occasions. In addition, environmental actions were often justified by referring to savings gained from energy-saving activities and considerate use of natural resources. Interestingly, most comments about environmental changes were mentioned in connection with the interviewees' personal lives rather than relating to their businesses and their operations. 
In the smaller firms, the valuation of nature as such was brought up more often than in the larger companies. The nature and fauna (also flora) were valued and respected for their own sake, not just in the sense of them enabling profit-making of the enterprise. Space and tranquillity were also valued in smaller companies: Micro-entrepreneurs more often showed fear of crowding and were not in favour of plans to build the destinations more densely. Moreover, if nature's interests/wellbeing and profit making were in conflict, nature (or animals as representatives of nature) was prioritised.

'Well, then we have this reindeer park on top of the fell together with the other reindeer operator...It is like a 170 hectare wide fenced area, and we have ten reindeer in there at the moment. No, last year we had more, but then again when it is not natural for the reindeer...it feels like you do not dare to put them all in there.' (microentrepreneur, Lapland)

'We are not going to buy ATVs (all-terrain-vehicles) as even though we are in this snowmobile business we are green souls to that extent that ATVs cause much more harm to nature and we do not want them.' (microentrepreneur, Lapland)

In general, future orientation was one important principle guiding the environmental actions of entrepreneurs in Finland. Even though not all entrepreneurs were planning to hand over the company to their offspring, they often referred to their kids when justifying the need to act in environmentally friendly ways. Also, the thought of the tourists as becoming more and more 'green' and environmentally aware appeared often in interviews, especially in connection to future demand. 'Yes...and, well, at our place of course now that we are an organic farm and so on, and as I said, I believe in the development of green tourism.' (microentrepreneur, Central Finland) 
'There are plenty of reasons for that [environmentally friendly action]. That our customers are extremely aware, environmentally conscious nowadays, so they kind of want it, so it is a competitive advantage.' (microentrepreneur, Lapland)

\section{The role of the state and other stakeholders, collaboration, development}

The entrepreneurs did not consider direct financial support from the government necessary. Rather, entrepreneurs' expectations for the state included provision and dissemination of information, project funding, tax concessions and subsidiaries for environmentally friendly actions, and stricter environmental laws. In addition, local public agencies (municipalities) should implement fair landuse planning, take responsibility for the services of the operational environments (basic infrastructure and certain non-commercial tourism activities, e.g. cross-country skiing tracks), and apply funding and realise development projects.

Thoughts about collaboration and distribution of responsibilities between the enterprises varied. The smaller enterprises considered the bigger enterprises as holding a more central role in all development activities at the destination level. They also believed that the larger, more responsible enterprises were already discussing the potential threat of climate change between them, without the smaller enterprises being informed yet. In a sense, the representatives of bigger enterprises agreed with that, but did not emphasise the matter.

'I think it is so that as small entrepreneurs they have of course a smaller role and that is better. So that the bigger (companies) pull the smaller ones. I think it has been a good division in that way.' (microentrepreneur, Lapland)

'It [climate change] is there in the background and kept in mind... and I would say that, or my impression is that all these responsible, significant enterprises, in one way or another, think about 
it among themselves and it is like the change is happening between the ears.' (microentrepreneur, Lapland)

Collaboration between enterprises, especially in marketing, but also in other aspects, was considered crucial. However, the entrepreneurs had strong views about their own operational territory, and did not provide a favourable review of all of their collaborators. True collaboration was sometimes hindered due to personal conflicts between entrepreneurs, and having good relationship with the focal/leading operators in the destination was considered important for the survival, and even the debut of the businesses. The entrepreneurs in the programme service industry were suspicious about new employees and other than paying customers attending their programs/activities because of fear of their unique idea/activity/service being stolen and utilised in other enterprises. Besides plagiarism, the poor quality of similar services sometimes concerned the entrepreneurs.

'But if you think about that Santa Claus thing [special Christmas activity], even though we've done it for several years already, we have not really allowed any others in there. And we very carefully consider who we'll let work there so that it does not suddenly happen that it slips out of our hands.' (microentrepreneur, Lapland)

'Well, it is similar phenomenon when you have Esso and Shell and Teboil in the same spot then nobody is doing good business...it is a very annoying characteristic when someone comes next to you and starts doing [business] a bit cheaper and snatches some product from your lists and makes a bit stripped-down version and cheaper, and does not put any effort into marketing, those are based exactly on that that there is some pre-existing [company/product] and when that is fully booked, then you in that way manage to lure customers inside [to sell your product to them]. It is very annoying.' (microentrepreneur, Lapland) 
Collaboration was not always visible, but occurred in informal ways. Entrepreneurs were helping their neighbour enterprises, and recommended them to their customers if they were sold out or if the tourists were after some other kind of activities. However, this kind of collaboration did not take place between all enterprises and was not always two-way collaboration.

'There is no collaboration between the enterprises even though they brag about it so much. ... It probably has to do with people and that we have always had that kind of business culture in here. ... They don't give credit to us. But if we are full, we do direct customers to those who don't buy [subcontract] from us. But I can call there and ask if they have (space in their husky programs) and can I direct these customers there. Because that is not away from us. It is about the customer who gets the experience and so.' (microentrepreneur, Lapland)

When it comes to development plans, the smaller entrepreneurs sometimes felt that their voices were not heard. In addition, the non-locals or new-comers considered themselves to be left out of decision-making concerning destination development and marketing. This leads to frustration, breakaways from destination development networks and development of blocs of entrepreneurs sharing similar views. Especially growth-oriented development was sometimes found to be alien among the smaller enterprises, as it may decrease the quality of the operational environment and this way also worsen the tourist experience.

'... and then there are also those kinds offorces here at this destination, so that kind of cold business investing and thinking, and is that kind of part of that world, and probably also some of the municipality's officials are tied into that world and so...and that is something that does not always fit for entrepreneurs...' (microentrepreneur, Lapland) 


\section{Discussion}

The lifestyle factors discussed by e.g. Ateljevic and Doorne (2000), Bredvold and Skålen (2016), and Lundberg and Fredman (2012) are evident among the participants of this study. The personal relationship and interest concerning the company's future are highly emphasised in the talks of nature-based tourism entrepreneurs. This applies regardless of the size of the enterprise. Also, Reijola's and Komppula's (2007) finding that earning money is not necessarily the primary motivator for running a nature-based tourism enterprise, is supported in the discussions.

Entrepreneurship in family-owned companies relates strongly with being able to be in control of what one does, achieving success from hard work, and coping with difficulties on your own (or with the help of the family members). It is possible that this kind of 'entrepreneurial' thinking increases the entrepreneurs' trust in their ability to survive in a changing climate, as these characteristics can be related especially to the motivational factors discussed by Steiner and Atterton (2015). Being proud of one's business and the quality of services/products may also increase resilience: in order to provide their customers high-quality services, the entrepreneurs need to be innovative and able to cope in varying conditions (Tervo, 2008). Short-term planning timescales may further increase flexibility and thus add the enterprise's resilience. On the other hand, coping on your own may prevent the diffusion or dissemination of climate resistant product and service ideas.

The entrepreneurs also admit that they are experts in their own field only, and welcome information from other sources. The inputs from researchers are appreciated, and entrepreneurs encourage scientists to contribute to tourism-related knowledge that can be applied in practice as well. On the other hand, entrepreneurs may refer to a lack of education when facing certain environmental issues: they do not have the needed knowledge and therefore they do not have to ponder climate 
change and its consequences. This leads us back to the positioning of entrepreneurs as change agents (see Vesala \& Niska, 2013) - their capability to act as agents creating change in terms of environmental issues may be hindered due to the high knowledge needs associated with them. This is something that researchers should also acknowledge when planning and implementing research basic research has its value, but there is a call for applied studies that can actually help the industry to better prepare for changes in the environment and climate.

Not surprisingly, collaboration seems to have a central role at the destination level. Power struggles hinder both collaboration and development, but not at all destinations. In addition, personal characteristics of the entrepreneurs are also emphasised, especially in smaller companies, where the owner may be the only worker: Personality can impact collaboration activity and attitudes towards other enterprises. For future survival and development, it is important to continue studying networking and collaboration within destinations. Trust issues are also important, as the fear of plagiarism may prevent the spread of ideas. This is of course understandable, but it may also negatively affect adaptation and mitigation, if innovative ideas that help in adapting or mitigating are only shared with trusted family members. Therefore, development of trust and collaboration at the destination level is an issue that may require extra support from 'neutral' and mediating stakeholders, such as public agencies. This supports Hall's (2010) views about the state's role in tourism development remaining important and even being emphasised because of recent economic and natural crises or disasters. However, attention must be paid so that state or regional authorities' actions do not skew development and competition or the relationships between tourism enterprises. In addition, governance has a key role in creating policy environments, which are supporting and enhancing rather than hindering. 
Relying on public institutions and the state as creators of environmental laws and deliverers of information can also link to the aspect discussed by Hall, Prayag and Amore (2017). They discuss the role of public agencies in helping to solve the problems by, for example, changing the timing of school holidays and planning and maintaining infrastructures that are more resistant to climatic or other changes. In the case of these kind of changes with slow rate of occurrence, it is possible that they are not considered or perceived significant (Hall, Prayag \& Amore, 2017) in a way that would cause changes in behaviour at individual or business scale. Rather, the public agencies are left to deal with them. The rate of change also relates with planning and development timescales - in smaller enterprises climate change may be considered a phenomenon, which does not affect current decision-making, like in the example of the investments on snowmobiles.

Finally, according to these results, there are certain differences in the ways the entrepreneurs talk about the natural environment. Even though all respondents acknowledge environmental values, the representatives of the smaller companies seem to reflect on the condition of nature more often in their responses. It is possible that the representatives of the larger enterprises are not in constant contact with nature during their everyday work and this affects their way of approaching the topic. Nevertheless, this is also an interesting aspect. Can one state on this basis that the smaller enterprises are more environment friendly than the larger ones? And if so, what happens, when the smaller enterprises believe that the bigger ones should have a leader-ship role and the smaller ones follow their actions? If that does not happen, then who will take the needed steps towards mitigation and adaptation? Is it possible that the green tourists, mentioned by some entrepreneurs, will be able to lead the change? In addition, the contradictory views concerning what is good for the tourism industry and environment may hinder mitigation activities. For example, more dense destinations are often good in pure ecological means (the negative impacts are not spread that far, energy- 
efficiency, etc.), but dense development is not necessarily welcomed by all entrepreneurs - for example in the case of those lifestyle entrepreneurs who greatly value wilderness.

One aspect that is missing from this study is the gender and its impact on (community) resilience (e.g. Bakas, 2017); unfortunately the data does not allow examination from that perspective. Another aspect that could be taken into account in the future is the enterprise size. There is some, but very weak indication, that the profit and growth of the business are less valued in micro enterprises than in larger companies. One explanation may be the fact that in larger companies the income of several employees is dependent on profits while in one-man enterprises the implications of low turnover mainly affect only one person. However, the data is not sufficient for making generalisations between micro-, small- and medium-sized enterprises, which may be an interesting topic for future research activities.

\section{Conclusions}

In general, the findings of this study support previous research about tourism entrepreneurship, with links to close family ties, attitudes concerning profit making and being able to maintain a certain lifestyle. In addition, the interviews analysed in this study have revealed some aspects that may impact tourism businesses' behaviours and reactions in relation to climate change and environmental issues in general. The study sheds some light on factors potentially affecting tourism entrepreneurs' reactions to changing climate.

Even though the data analysed does not allow making generalisations, the findings indicate that adaptation-related decision-making in nature-based tourism enterprises may relate with the so called lifestyle-factors or characteristics of the entrepreneurs. These factors have been studied previously 
in contexts other than climate change, and this study indicates strongly that they should be examined more thoroughly in the future. Understanding these characteristics and their relation to adaptation (and mitigation) decision-making at the tourism-enterprise-level rather than at a destination-scale is important, as individual enterprises and their actions may influence communitylevel resilience.

The results indicate that entrepreneurs' values and attitudes (i.e. entrepreneurial characteristics) may both hinder and advance adaptation. The entrepreneurs' high confidence in their own survival, for example, may lead to enterprises behaving reactively rather than proactively towards GEC. This affects community resilience negatively. On the other hand, this confidence is justifiable, as entrepreneurs have been struggling and surviving challenges throughout their existence - a changing environment may lead to new innovations that can positively influence the whole destination/community.

Finally, it is possible that the rate of change and the scale affect remarkably the considerations and reactions about climate change. On one hand, the entrepreneurs representing smaller businesses can have more flexibility in terms of shorter planning periods and scale of operations. On the other hand, this flexibility may again also lead to reactivity rather than proactivity as the smaller businesses trust the bigger businesses to take a leading role in destination scale development. The pace of GEC from the point of view of a micro-enterprise is very slow, and if the changes are mostly considered from the point of view of personal life, it may take some time (and require more dramatic changes in the environment) before entrepreneurs will truly start to implement businessrelated actions. 


\section{References}

Ateljevic, I., \& Doorne, S. (2000). 'Staying within the fence': Lifestyle entrepreneurship in tourism. Journal of Sustainable Tourism, 8(5), 378-392.

Ateljevic, J., \& Li, L. (2009). Tourism entrepreneurship - concepts and issues. In Ateljevic, J. \& Page, S (Eds.), Tourism and entrepreneurship. International perspectives (pp. 9-32). Oxford, Elsevier.

Bakas, F. E. (2017). Community resilience through entrepreneurship: the role of gender. Journal of Enterprising Communities: People and Places in the Global Economy, 11(1), 61-77.

Becken, S. (2005). Harmonising climate change adaptation and mitigation: The case of tourist resorts in Fiji. Global Environmental Change, 15, 381-393

Becken, S. (2008). Report. The UN Climate Change Conference, Bali: What it means for tourism? Journal of Sustainable Tourism, 16(2), 246-248.

Becken, S. (2013). Developing a framework for assessing resilience of tourism sub-systems to climatic factors. Annals of Tourism Research, 43,506-528.

Bredvold, B., \& Skålen, P. (2016). Lifestyle entrepreneurs and their identity construction: A study of the tourism industry. Tourism Management, 56, 96-105.

Brouder, P., \& Lundmark, L. (2011). Climate change in Northern Sweden: intra-regional perceptions of vulnerability among winter-oriented tourism businesses. Journal of Sustainable Tourism, 19(8), 919-933.

Browne, S., \& Hunt, L. (2007). Climate change and nature-based tourism, outdoor recreation, and forestry in Ontario: Potential effects and adaptation strategies (Thunder Bay: Ontario Ministry of Natural Resources). Available at 
http://www.mnr.gov.on.ca/stdprodconsume/groups/lr/@mnr/@climatechange/documents/doc ument/276926.pdf (Accessed 20.8.2014).

Burnard, K. \& Bhamra, B. (2011). Organisational resilience: development of a conceptual framework for organisational responses. International Journal of Production Research, 49(18), 5581-5599.

Dodds, R., \& Graci, S. (2009). Canada's tourism industry - Mitigating the effects of climate change: A lot of concern but little action. Tourism and Hospitality Planning \& Development, 6(1), 3951.

Hall, C.M. (2006). New Zealand tourism entrepreneur attitudes and behaviours with respect to climate change adaptation and mitigation. International Journal of Innovation and Sustainable Development, 1(3), 229-237.

Hall, C. M. (2010). Crisis events in tourism: Subjects of crisis in tourism. Current Issues in Tourism, 13, 401-417.

Hall, C. M., Prayag,G., \& Amore, A. (2017). Tourism and resilience: Individual, organisational and destination perspectives. Bristol and Blue Ridge Summit: Channel View Publications.

Hambira, W. L., Saarinen,J., Manwa, H., \& Atlhopheng, J. (2013). Climate change adaptation practices in nature-based tourism in Maun in the Okavango Delta area, Botswana: how prepared are the tourism businesses? Tourism Review International, 17(1), 19-29.

Hjorth, D. (2003). Rewriting entrepreneurship - for a new perspective on organisational creativity. Lund: Copenhagen Business School Press.

Hübner, A. (2014). Concepts of culture and tourism adaption to climate change in Tuvalu. Tourism, Culture \& Communication, 13(2), 79-94. 
Iversen; I., \& Jacobsen, J. Kr. S. (2016). Migrant tourism entrepreneurs in rural Norway. Scandinavian Journal of Hospitality and Tourism, 16(4), 484-499.

Jones, C., \& Spicer, A. (2009). Unmasking the entrepreneur. Cheltenham, UK: Edward Algar.

Kaján, E. \& Saarinen, J. (2013) Tourism, climate change and adaptation: a review. Current Issues in Tourism, 16, 167-195.

Kaján, E., Tervo-Kankare, K. \& Saarinen, J. (2014). Cost of adaptation to climate change in tourism: Methodological challenges and trends for future studies in adaptation. Scandinavian Journal of Hospitality and Tourism, 15(3), 311-317.

Leiserowitz, A. (2006). Climate change risk perception and policy preferences: the role of affect, imagery, and values. Climatic Change, 77, 45-72.

Lundberg, C., \& Fredman, P. (2012). Success factors and constraints among nature-based tourism entrepreneurs. Current Issues in Tourism, 15(7), 649-671.

McNaughton, R. B., \& Gray, B. (2017). Entrepreneurship and resilient communities - introduction to the special issue. Journal of Enterprising Communities: People and Places in the Global Economy, 11(1), 2-19.

Petäjistö, L., \& Shelby, A. (2012). Luontomatkailun yritystoiminta Suomessa (Nature-based tourism and enterprise activities in Finland). Metlan työraportteja 246. Available from http://www.metla.fi/julkaisut/workingpapers/2012/mwp246.htm (accessed 15.10.2017).

Pollock, A. (2008). The climate change challenge implications for the tourism industry. A discussion paper. The Icarus Foundation. Available from http://www.theicarusfoundation.com/pdf/Icarus_Discussion_Paper\%20MAR_08.pdf (accessed 20.8.2014). 
Reijonen, H., \& Komppula, R. (2007). Perception of success and its effect on small firm performance. Journal of Small Business and Enterprise Development, 14(4), 689-701.

Saarinen, J., \& Tervo, K. (2006). Perceptions and adaptation strategies of the tourism industry to climate change: The case of Finnish nature-based tourism entrepreneurs. International Journal of Innovation and Sustainable Development, 1(3), 214-228.

Saarinen, J., \& Tervo, K. (2010) Sustainability and emerging awareness to changing climate: Tourism industry's knowledge and perceptions of the future of nature-based winter tourism in Finland. In C.M. Hall \& J. Saarinen (Eds.), Tourism and change in Polar Regions: Climate, environment and experiences (pp. 147-64). London and New York, NY: Routledge.

Sampaio, A., Thomas, R., \& Font, X. (2012). Small business management and environmental engagement. Journal of Sustainable Tourism, 20(2), 179-193.

Scott, D., Hall, C. M., \& Gössling, S. (2012). Tourism and climate change: impacts, adaptation and mitigation. New York, NY and Abingdon: Routledge.

Shaw, G., \& Williams, A. (2004). From lifestyle consumption to lifestyle production: Changing patterns of tourism entrepreneurship. In Thomas, R. (Ed.), Small firms in tourism. International perspectives (pp. 99-114). Amsterdam: Elsevier.

Schumpeter, J. A. (1934). The theory of economic development. Cambridge. MA: Harvard University Press.

Solvoll, S., Alsos, G. A., \& Bulanova, O. (2015). Tourism entrepreneuship - Review and future directions. Scandinavian Journal of Hospitality and Tourism, 15:sup1, 120-137.

Steiner, A., \& Atterton, J. (2015). Exploring the contribution of rural enterprises to local resilience. Journal of Rural Studies, 40, 30-45. 
Tervo, K. (2008). The operational and regional vulnerability of winter tourism to climate variability and change: The case of the Finnish nature-based tourism entrepreneurs. Scandinavian Journal of Hospitality and Tourism, 8(4), 317-332.

Tervo-Kankare, K. (2011). The consideration of climate change at the tourism destination level in Finland: Coordinated collaboration or talk about weather? Tourism Planning \& Development, 8(4), 399-414.

Vesala, K. M., \& Niska, M. (2013). Sosiaalipsykologia ja maaseutututkimus: identiteettejä, toimijuutta, yrittäjyyttä (Social psychology and rural studies: identities, actorhood and entrepreneurship). Maaseudun uusi aika, 21: 2-3, 34-46.

Vesterinen, N. (2017). 4 hyvää syytä panostaa matkailuun (4 good reasons to focus on tourism). Työ- ja elinkeinoministeriö.

Walker, B., Holling, C. S., Carpenter, S. R., \& Kinzig, A. (2004). Resilience, adaptability and transformability in social-ecological systems. Ecology and Society 9(2), article 5. 
Table 1. Interviewees

\begin{tabular}{|l|l|}
\hline Field of operation of the interviewed enterprises & \\
\hline Accommodation and restaurant enterprises & 8 \\
\hline Program service and skiing enterprises & 8 \\
\hline Accommodation and restaurant and program services & 3 \\
\hline Total & 19 \\
\hline
\end{tabular}

